duction in plants? Within a single habitat, such as calcareous grassland, there is a considerable range of seed production per plant, for example, Thesium humifusum, produces 100 per plant; Polygala calcarea, 270; Carlina vulgaris, 680; Anacamptis pyramidalis, 35,000; Senecio jacobaea, 50,000; Orchis maculata, 56,000 and Orobanche elatior, 98,000. As Salisbury points out, these figures relate most closely to the relative risks experienced with different mechanisms of seed dispersal, wind being more risky (and therefore more wasteful) than animal dispersal.

Salisbury (1976) quotes Juncus effusus and J. tenuis as an example of contrasting seed production resulting from the use of different dispersal mechanisms. J. effusus produces between 1.5 and 3 million seeds per plant (wind dispersed) whereas $J$. tenuis produces 3,000-4,000 (adhesion to animais and vehicles). Thus two species of the same genus, both occupying unstable habitats, in the successional sense, differ in their seed production by three orders of magnitude.

Evidently there are several evolutionary answers to any environmental problem. In a given set of conditions, the output of seed from a taxon is influenced by such factors as the relative importance of vegetative reproduction and the seed dispersal mechanism used, as well as any response to the stabiltiy $(r-K)$ gradient. The simplest answers may be the most attractive, but they are not necessarily the most complete ones.

\section{Chemistry does not define environment}

from Peter J. Smith

IN the past, many workers have placed great reliance on chemical characteristics as indicators of the geological, and especially crustal, environments in which Archean basalts were emplaced. Some, for example, have seen the lack of crustal contamination observed in low-potassium tholeiites in greenstone belts as an important argument against the presence of sialic crust beneath the successions. Others have regarded the calc-alkaline affinities of certain greenstone basalts as evidence of an original island arc environment. According to Gill and Bridgwater (Earth planet. Sci. Lett., 29, 276; 1976), however, the use of chemical comparisons between modern basalts and Archean basic rocks to identify ancient environments must now be regarded as a questionable procedure.

Gill and Bridgwater base their case on a study of the Ameralik dykes of West Greenland. This heterogeneous group of metamorphosed minor basic

\title{
Aggression in sticklebacks
}

\section{from John Krebs}

THE question of how different types of aggression in animals are related to one another has been a source of continual controversy. Aggressive behaviour in natural conditions is usually seen in competitive social encounters between members of the same species, for example in territorial defence and dominance disputes. On the other hand many experimental laboratory studies have been concerned with attacks directed at inanimate objects or at members of another species (for example a rat attacking a mouse). There have been few attempts to examine whether or not aggression in these different contexts depends on a common internal mechanism.

In a recent study F. A. Huntingford (Anim. Behav., 24, 245-260; 1976) has examined this question. Using that traditional ethological beast, the three-spined stickleback, she carried out a series of experiments to test whether individual males which were highly aggressive in one context would also score high in other situations. It has long been known that a male stickleback will vigorously attack a 'rival' male which is presented to him near his nest in a glass tube. Huntingford used this technique to compare the aggressive response, measured by biting and lunging, to a rival male, a male of the closely related but

intrusions, emplaced in 3,700-3,600 Myr old gneisses forming part of the western edge of the North Atlantic craton, has been affected variably by subsequent magmatic and tectonic events which enable a lower limit of 3,040 Myr to be placed on the dykes' ages. The total area of older sialic crust cut by the dykes exceeds $12,000 \mathrm{~km}^{2}$, although there is no a priori reason for supposing all the dykes to have been emplaced in a single episode nor any for supposing all the dykes to have been derived from the same parent magma.

And the chemistry of the dykes suggests that any such suppositions would indeed be wrong. Although all the dykes studied were basaltic, their compositions ranged from that of primitive basalts reminiscent of modern oceanic basalts to more differentiated types akin to iron-rich tholeiites of modern continental flood basalt provinces. Some of this variation is undoubtedly due to subsequent metasomatism; but Gill and Bridgwater conclude from Rare Earth Element patterns, Ni, Sr, $\mathrm{Ti}$ and $\mathrm{Zr}$ contents and other chemical quite distinct ten-spined stickleback, and a female smooth newt (a common inhabitant of the streams favoured by sticklebacks). Briefly, she found that the aggression scores for individual males to all three stimuli were well correlated. In two further experiments, Huntingford measured the reaction of the same group of males to a predator (a pike) and to being placed in an unfamiliar tank. She analysed these results by Principle Components Analysis and was able to identify a group of behaviours which could be classified as indicating 'boldness'; these included approaching the pike and showing normal swimming movements. Individuals which had scored high on the aggression tests also tended to be bold in the face of a predator and in an unfamiliar tank, and this was not simply a result of higher overall activity.

These results suggest that territorial aggression and aggression against predators may depend in part on common internal factors. Huntingford points out that this makes evolutionary sense, because stickleback populations exposed to heavy predation should not only tend to become timid in the presence of a predator, but also make themselves inconspicuous by not engaging in vigorous territorial displays.

indicators that much of it reflects a range of primary compositions.

If this is so, the dilemma is clear. The ridge-like Ameralik basalts, for example, were evidently not intruded into early ocean floor, although had they not equally evidently been intruded into granite gneiss their chemistry could have been taken incorrectly to indicate an oceanic origin. Moreover, these same ridge-like basalts are comparable in composition to greenstone successions in South Africa and Australia and some greenstone belts in the Canadian Shield. It is most reasonable, claim Gill and Bridgwater, to assume that the primary compositional variations represent differences in the depth of melting in the mantle and/or the speed at which the magmas rose to the surface. In other words, the variations reflect changes in the melting régime and/or degree of differentiation rather than differences in crustal environment (oceanic, continental, island arc). Ergo, inferences about crustal environment drawn from chemistry alone must be suspect. 